\title{
BMJ Open Evaluating the safety and dosing of drugs in patients with liver cirrhosis by literature review and expert opinion
}

\author{
Rianne A Weersink, ${ }^{1,2}$ Margriet Bouma, ${ }^{3}$ David M Burger, ${ }^{4}$ Joost P H Drenth, ${ }^{5}$ \\ Nicole G M Hunfeld, ${ }^{6}$ Minke Kranenborg, ${ }^{7}$ Margje H Monster-Simons, ${ }^{8}$ \\ Sandra A W van Putten, ${ }^{9}$ Herold J Metselaar, ${ }^{10}$ Katja Taxis, ${ }^{2}$ \\ Sander D Borgsteede ${ }^{1,11}$
}

To cite: Weersink RA, Bouma M, Burger DM, et al. Evaluating the safety and dosing of drugs in patients with liver cirrhosis by literature review and expert opinion. BMJ Open 2016;6: e012991. doi:10.1136/ bmjopen-2016-012991

- Prepublication history for this paper is available online. To view these files please visit the journal online (http://dx.doi.org/10.1136/ bmjopen-2016-012991).

Received 9 June 2016 Revised 17 August 2016 Accepted 16 September 2016

CrossMark

For numbered affiliations see end of article.

Correspondence to Dr Sander Borgsteede; s.d.borgsteede@rug.nl

\section{ABSTRACT \\ Introduction: Liver cirrhosis can have a major impact on drug pharmacokinetics and pharmacodynamics. Patients with cirrhosis often suffer from potentially preventable adverse drug reactions. Guidelines on safe prescribing for these patients are lacking. The aim of this study is to develop a systematic method for evaluating the safety and optimal dosage of drugs in patients with liver cirrhosis.}

Methods and analysis: For each drug, a six-step evaluation process will be followed. (1) Available evidence on the pharmacokinetics and safety of a drug in patients with liver cirrhosis will be collected from the Summary of Product Characteristics (SmPC) and a systematic literature review will be performed. (2) Data regarding two outcomes, namely pharmacokinetics and safety, will be extracted and presented in a standardised assessment report. (3) A safety classification and dosage suggestion will be proposed for each drug. (4) An expert panel will discuss the validity and clinical relevance of this suggested advice. (5) Advices will be implemented in all relevant Clinical Decision Support Systems in the Netherlands and published on a website for patients and healthcare professionals. (6) The continuity of the advices will be guaranteed by a yearly check of new literature and comments on the advices. This protocol will be applied in the evaluation of a selection of drugs: (A) drugs used to treat (complications of) liver cirrhosis, and (B) drugs frequently prescribed to the general population. Ethics and dissemination: Since this study does not directly involve human participants, it does not require ethical clearance. Besides implementation on a website and in clinical decision support systems, we aim to publish the generated advices of one or two drug classes in a peer-reviewed journal and at conference meetings.

\section{INTRODUCTION}

Liver cirrhosis is a slowly progressive disease characterised by fibrosis and conversion of normal liver architecture into structurally abnormal nodules. Liver cirrhosis results from

\section{Strengths and limitations of this study}

- This is the first protocol describing a six-step method to develop advices about the safety of drugs in patients with liver cirrhosis. The first four steps involve gathering evidence and an assessment by an expert panel. Steps five and six consist of implementing prescribing advice in all relevant clinical decision support systems in the Netherlands and regularly updating the advices.

- We have designed a safety classification to support healthcare providers and patients to efficiently judge drug safety in liver cirrhosis.

- A potential limitation of this protocol is the number of published studies available concerning the use of drugs in patients with liver cirrhosis. However, the combination with expert opinion will make it possible to give specific advices.

ongoing inflammation of the liver. ${ }^{1}$ Clinical symptoms ensue because the hepatic architecture is affected, which results in increased vascular resistance in the liver and portal hypertension. ${ }^{1}$ Liver cirrhosis has an important impact on healthcare worldwide. In 2010, more than one million people died of liver cirrhosis, which was almost $2 \%$ of global deaths. ${ }^{23}$ The Child-Pugh score classifies the severity of liver cirrhosis and predicts mortality. ${ }^{4}$ It is also recommended by the medicine registration authorities in Europe and the USA for use in pharmacokinetic studies. ${ }^{56}$

The liver is the main organ for metabolism and detoxification of endogenous and exogenous substances. Several pathophysiological changes that occur in liver cirrhosis influence this detoxification of exogenous substances, that is, drug pharmacokinetics. ${ }^{7-9}$ Portal vein shunting increases oral absorption of drugs with a high hepatic extraction ratio through a bypass of the liver. Decreased plasma protein synthesis causes lower plasma 
protein concentrations and possibly a higher fraction of unbound drug. A reduction or impairment of drugmetabolising enzymes in the liver may cause reduced metabolism. These changes often result in an elevated drug exposure, possibly causing side effects and toxicity. ${ }^{7-9}$ It is also important to consider changes in pharmacodynamics. Hence, the efficacy of drugs could be different in patients with liver cirrhosis. Moreover, patients with cirrhosis are more vulnerable to certain adverse drug reactions (ADRs), such as effects on coagulation or nephrotoxicity. ${ }^{78}$

In patients with liver cirrhosis, $20 \%$ of the drugs are dosed incorrectly and almost $30 \%$ of patients with cirrhosis suffer ADRs. ${ }^{10}$ It is estimated that nearly $80 \%$ of these ADRs could be prevented. ${ }^{10}$ There are studies available describing the pharmacokinetic alterations for a wide range of drugs in patients with cirrhosis. ${ }^{8}{ }^{10-14}$ All these studies are of great value and can be very useful for healthcare professionals. However, they can be difficult to obtain and interpret for a busy healthcare professional not frequently dealing with patients with cirrhosis. What is missing is the translation of all literature into a regularly updated and easy manageable source of information on safe prescribing in patients with liver cirrhosis. $^{15}$

This study wants to address this problem by developing advices for the safe use of medications in patients with liver cirrhosis. To guarantee the quality of these advices, it is important that the method for evaluating is performed in a uniform, transparent manner leading to a standardised report. ${ }^{16}$ Furthermore, advices need to be manageable by all healthcare professionals dealing with patients with liver cirrhosis. ${ }^{16}$ We intend to develop concrete and up-to-date advices to prevent alert fatigue and dissatisfaction by healthcare professionals. The aim of this study is to describe the systematic method used for evaluating the safety and optimal dosage of drugs in patients with liver cirrhosis.

\section{METHODS}

Six steps will be performed for evaluating a drug (figure 1). Below, the six steps are described in detail. Steps 1-3 will be performed by a pharmacist with experience in the evaluation of drug safety in the context of clinical decision support systems (RW). The critical steps are checked by a second pharmacist/epidemiologist (SB).

\section{Step 1: collection of evidence}

\section{Summary of Product Characteristics (SmPC)}

Information concerning the pharmacokinetics of the drug in healthy volunteers and patients with liver cirrhosis will be collected from the official Product Characteristics as published by the responsible authorities European Medicines Agency (EMA), Food and Drug Administration and the Medicines Evaluation Board in the Netherlands. For products registered by the EMA, the European Public Assessment Report will be searched on information about dosage in liver cirrhosis. Special warnings regarding the safety of the drug in patients with liver cirrhosis will also be collected.

\section{Literature search in electronic databases}

The search in electronic literature databases aims to review published literature about the alterations in pharmacokinetic parameters and the safety of the drug in patients with liver cirrhosis.

Criteria for inclusion in the literature review are: (1) the study investigates patients with liver cirrhosis, (2) the study concerns the drug of interest and (3) the outcome of the study is safety (ie, adverse events) and/or (altered) pharmacokinetics. Studies with and without a control group will be included. If a drug is compared to another intervention, data about the control group will be included in the data extraction. There will be no limit to the time periods searched.

Exclusion criteria are: (1) animal studies, (2) cellular and molecular research, (3) studies in patients with other hepatic diseases, such as hepatocellular carcinoma, nonalcoholic fatty liver disease or primary biliary cholangitis, that do not mention the inclusion of a subpopulation with liver cirrhosis and (4) studies about drug-induced liver injury in patients without liver cirrhosis.

\section{PubMed+EMBASE}

These databases will be searched (this includes reviews published by the Cochrane library) by the search strategy outlined in table 1. A more specific search will be performed if there is excessive literature. In this case, a stepwise search strategy will be used starting with PubMed as a database. Filters that indicate studies with a high level of evidence will be used to limit the number of studies. The pharmacists responsible for the collection of evidence will judge whether sufficient data are collected to answer the research question. This step is checked by another pharmacist and will be discussed and finally confirmed by the expert panel.

\section{Citation tracking}

Additional articles will be obtained through citation snowballing to locate primary sources.

\section{Step 2: data extraction and presentation}

The following characteristics of included studies will be extracted: study design, number and characteristics of included patients and controls (eg, severity of liver cirrhosis) and details on the intervention. Concerning the outcome(s), the following data will be extracted:

- (altered) Pharmacokinetics: data on pharmacokinetic parameters (eg, area under the curve (AUC), elimination half-life and steady state concentration) of the drug in patients with liver cirrhosis, preferably compared with patients without liver cirrhosis.

- Safety: data on the number of adverse events observed during use of the drug in patients with cirrhosis and on the consequences of these adverse 
Figure 1 Flow chart of the six-step process used per drug for evaluating the safety and optimal dosage in liver cirrhosis.

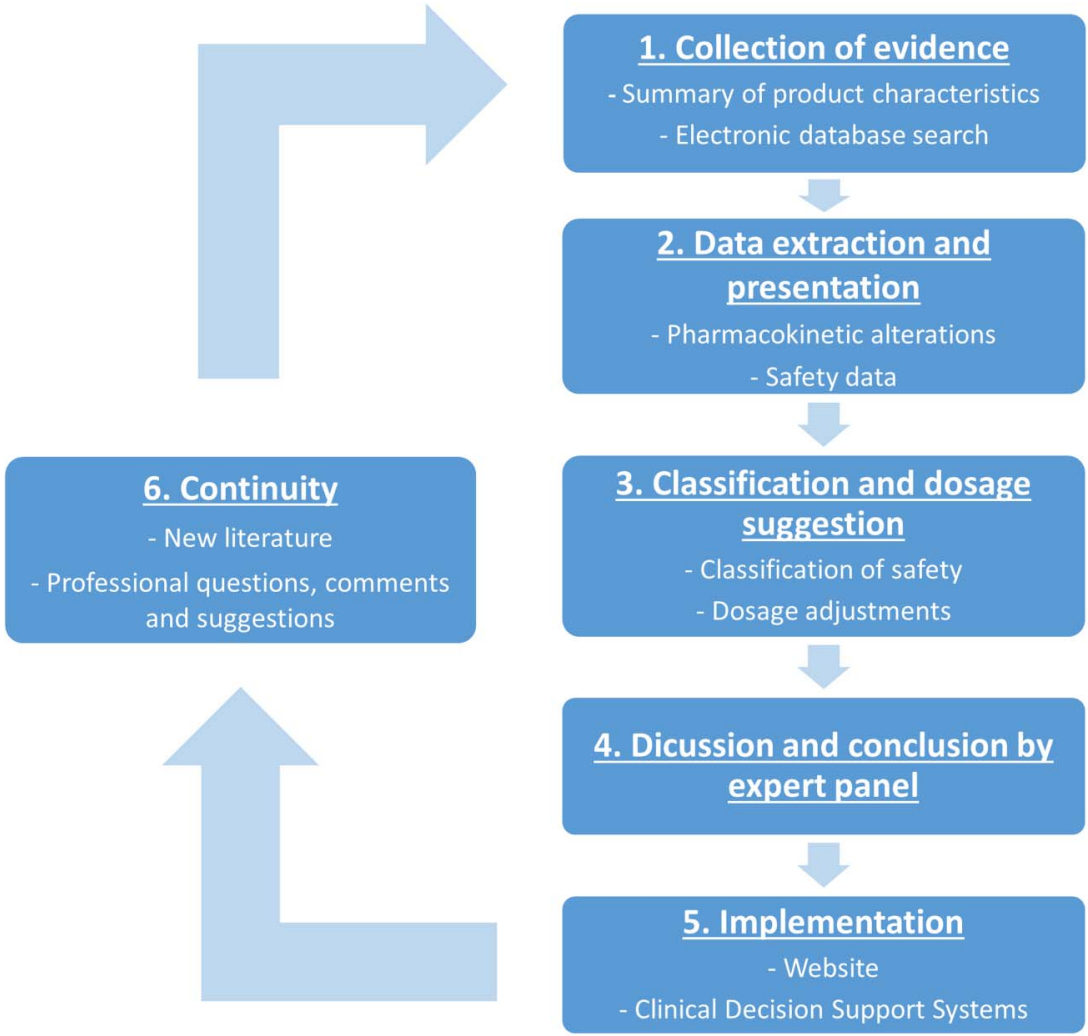

Table 1 Proposed search strategy for PubMed and EMBASE

\begin{tabular}{|c|c|}
\hline Database & Search query \\
\hline PubMed & $\begin{array}{l}\text { ("Liver cirrhosis"[Mesh] OR cirrho*[ti] OR } \\
\text { "hepatic impairment"[ti] OR "liver } \\
\text { impairment"[ti] OR "hepatic dysfunction"[ti] OR } \\
\text { "liver dysfunction"[ti] OR "hepatic } \\
\text { insufficiency"[ti] OR "liver insufficiency"[ti]) } \\
\text { AND ("X"[Mesh] OR "X"[tiab]) AND } \\
\text { "humans"[MeSH Terms] }\end{array}$ \\
\hline EMBASE & $\begin{array}{l}\text { 'liver cirrhosis'/exp OR cirrho*:ti OR 'hepatic } \\
\text { impairment':ti OR 'liver impairment':ti OR } \\
\text { 'hepatic dysfunction':ti OR 'liver dysfunction':ti } \\
\text { OR ‘hepatic insufficiency':ti OR 'liver } \\
\text { insufficiency':ti AND ('X'/exp OR 'X':ab,ti) AND } \\
\text { [humans]/lim }\end{array}$ \\
\hline
\end{tabular}

$\mathrm{X}$, name of drug to be evaluated.

events (eg, discontinuation of treatment, dose reductions), preferably compared with patients without liver cirrhosis.

Data will be reported in summary tables for each outcome and sorted by level of evidence. The level of evidence of each study will be assessed according to the criteria for treatment harms of the Oxford Centre for Evidence-Based Medicine. ${ }^{17}$ In a separate table, narrative reviews will be included as level five evidence to reflect on published expert opinions. The summary tables will be checked by a second pharmacist.
All data will be summarised in an assessment report. This standardised report will contain:

- Data from the SmPC

- Details on the electronic database search (search strategy, study selection process in a flow chart)

- Summary tables with pharmacokinetic and safety data

- References

\section{Step 3: classification and suggested dose}

All information from the report will be used to suggest a safety classification and a dose per individual drug, if applicable sorted by severity of liver cirrhosis. The severity will be expressed using the Child-Pugh classification. ${ }^{4}$

\section{Safety classification}

To support healthcare providers and patients to efficiently judge drug safety in liver cirrhosis, we designed a safety classification (table 2). For drugs in liver cirrhosis, we will use the following categories: safe, no additional risks known, additional risks known, unsafe and unknown. Drugs that have not been evaluated are placed in the category 'not yet classified'.

\section{Suggested dose}

Pharmacokinetic data will be used to judge whether a dose adjustment is necessary in patients with cirrhosis. It applies for most drugs that if the AUC is more than doubled, a dose reduction will be recommended. ${ }^{5}$ Exceptions are, for instance, drugs that do not have a concentration-effect relationship or drugs with a narrow therapeutic range. Both the proposed classification and 
Table 2 Safety classification of drugs used in liver cirrhosis

\begin{tabular}{|c|c|c|}
\hline & Description & Action \\
\hline Safe & $\begin{array}{l}\text { The drug has been evaluated in patients with liver } \\
\text { cirrhosis, and no increase in harm was found. The safety } \\
\text { of the drug is supported by pharmacokinetic studies and/or } \\
\text { safety studies over a long period. } \\
\text { It might be necessary to use an adjusted dose. }\end{array}$ & $\begin{array}{l}\text { This drug can be used by patients with liver } \\
\text { cirrhosis. }\end{array}$ \\
\hline $\begin{array}{l}\text { No additional } \\
\text { risks known }\end{array}$ & $\begin{array}{l}\text { Limited data suggest that this drug does not increase } \\
\text { harm in patients with liver cirrhosis in comparison with } \\
\text { persons without cirrhosis. Drugs estimated as 'minor } \\
\text { influenced by cirrhosis' based on pharmacokinetics* can } \\
\text { also be classified in this category if the expert panel } \\
\text { agrees. } \\
\text { It might be necessary to use an adjusted dose. }\end{array}$ & $\begin{array}{l}\text { The drug can be used in patients with liver } \\
\text { cirrhosis. } \\
\text { Adverse drug reactions need to be monitored. }\end{array}$ \\
\hline $\begin{array}{l}\text { Additional risks } \\
\text { known }\end{array}$ & $\begin{array}{l}\text { Limited data suggest an increase in patient harm in } \\
\text { patients with cirrhosis compared with persons without } \\
\text { cirrhosis. However, the number of studies is limited and/or } \\
\text { the studies show contradictory results about the safety in } \\
\text { patients with liver cirrhosis. }\end{array}$ & $\begin{array}{l}\text { This drug should preferably not be used in } \\
\text { patients with liver cirrhosis if there is a safer } \\
\text { alternative available. } \\
\text { Adverse drug reactions need to be monitored. }\end{array}$ \\
\hline Unsafe & $\begin{array}{l}\text { Data indicate that this drug is not safe in patients with liver } \\
\text { cirrhosis. }\end{array}$ & $\begin{array}{l}\text { This drug should be avoided in patients with } \\
\text { liver cirrhosis. }\end{array}$ \\
\hline Unknown & $\begin{array}{l}\text { For this drug, insufficient data are available to evaluate the } \\
\text { safety in patients with liver cirrhosis. }\end{array}$ & $\begin{array}{l}\text { This drug should preferably not be used in } \\
\text { patients with liver cirrhosis if there is a safer } \\
\text { alternative available. } \\
\text { Individual judgement of therapeutic need vs } \\
\text { additional risks in patients with liver cirrhosis. } \\
\text { Adverse drug reactions need to be monitored. }\end{array}$ \\
\hline $\begin{array}{l}\text { Not yet } \\
\text { classified }\end{array}$ & $\begin{array}{l}\text { The drug has not been evaluated for safety in patients } \\
\text { with liver cirrhosis. }\end{array}$ & No advice for action can be given \\
\hline
\end{tabular}

suggested dose are checked by a second pharmacist, before discussion by the expert panel.

\section{Step 4: discussion and conclusion by the expert panel}

An expert panel will evaluate the validity and clinical relevance of the initial classification, the suggested dose and the data extraction. This panel will meet five times during the study to discuss the assessment reports. Comments and opinions of the panel will be added to the initial report, such as recommendations for therapeutic drug monitoring or extra monitoring of liver function tests and/or clinical response. The final report is a combination of the available evidence and expert opinions. The expert panel will conclude by consensus. If there are different interpretations within the expert panel, these will be included as 'expert comments' in the assessment report.

The expert panel consists of the following specialists: the pharmacist responsible for the data collection, extraction and initial evaluation (RW), professionals with expertise regarding our two main outcomes; altered safety or pharmacokinetics in patients with liver cirrhosis (DB and $\mathrm{NH}$ ), representatives of the specialists responsible for prescribing: hepatologists (JD and HM), general practitioner $(\mathrm{MB})$, representatives of specialists responsible for dispensing: clinical pharmacists (DB and $\mathrm{NH})$, a community pharmacist (SvP), a clinical pharmacokinetics assessor of the Medicines Evaluation Board (MM-S) and two pharmacists working with the national drug databases in the Netherlands (Pharmabase and G-Standard: MK and SB). Each expert has specific expertise in the treatment of patients with liver cirrhosis, in clinical pharmacology and/or the implementation of the outcomes. The general practitioner and community pharmacist will contribute to the implementation from the perspective of primary care. The pharmacists working for the national drug databases will assure that the advices can be implemented in clinical decision support systems. There is also an epidemiologist (SB) in the expert panel who will pay attention to the methodology.

All conflicts of interest of the members of the expert panel will be identified, disclosed and published on the website (see implementation). The chair of the expert panel (SB) has no conflicts of interest.

\section{Step 5: implementation}

Advices about the safety of a drug and the optimal dosage in patients with liver cirrhosis will be implemented in the two national drug databases in the Netherlands (Pharmabase and G-Standard). This will generate specific alerts for healthcare professionals when they prescribe or dispense a drug with risks to a patient with liver cirrhosis. 
The advices will also be published on a website. On this website, a summary will be included which starts with the key recommendations (ie, safety classification of drug and dosing advices) and describes background information on the advice and body of evidence (ie, number of studies retrieved, number of participants and level of evidence of the studies). The full assessment report can be accessed through a hyperlink. The advices will be in Dutch, since they will be implemented in national clinical decision support systems. The summary of finding tables derived from the (English) literature will be left in English. Conflicts of interest of the members of the expert panel will be mentioned on the website.

There will also be a part on the website intended for patients with liver cirrhosis. This part will contain a simple, patient-friendly version of the advices with directions to consult their doctor or pharmacist in case of further questions. These advices will be made in collaboration with the Dutch Liver Patients Association. Before publication of the website, the finding and understanding of the content will be tested by patients and healthcare professionals. Via user testing, a group of patients and a group of healthcare professionals will test the website. ${ }^{18}$ If issues emerge from this testing, they will be solved and the process will be repeated until no more issues emerge.

\section{Step 6: continuity}

To assure up-to-date advices, literature searches will be saved and checked yearly for relevant literature. Comments from patients and professionals using the guidelines will be reviewed and included, if applicable. The expert panel will check yearly if the advices need to be updated based on their specific (clinical) expertise.

\section{Drugs to be evaluated}

A selection of drugs will be evaluated: (A) drugs used to treat (complications of) liver cirrhosis, such as ursodeoxycholic acid and $\beta$-blockers and (B) drugs that are prescribed frequently to the general population, such as antibiotics and analgesics. An overview of the drugs that will be evaluated in this study is presented in table 3 .

\section{DISCUSSION}

We have developed a systematic method to evaluate the safety and optimal dosage of drugs in patients with liver cirrhosis. Our method combines a systematic literature review with expert opinion and contains many aspects of the development of guidelines. We used the AGREE Reporting Checklist to ensure that important issues are included in the study protocol. ${ }^{25}$ Our approach will produce a standardised assessment report per drug. It is important that this report contains the information healthcare professionals need for clinical decisionmaking. In the development of an assessment report, we were inspired by a checklist that identifies the most important elements that should be included in drugdrug interaction management guidelines. ${ }^{16}$ One of the

\begin{tabular}{|c|c|}
\hline $\begin{array}{l}\text { Box A: drugs to treat } \\
\text { (complications of) liver } \\
\text { cirrhosis }^{19-24}\end{array}$ & $\begin{array}{l}\text { Box B: most frequently } \\
\text { used drugs in the general } \\
\text { population }\end{array}$ \\
\hline $\begin{array}{l}\text { Metabolic syndrome } \\
\text { Insulins } \\
\text { Oral antidiabetics } \\
\text { Dyslipidemia } \\
\text { Antilipemics } \\
\text { (anti) Hepatitis B/C } \\
\text { Nucleos(t)ide analogues } \\
\text { Interferon } \\
\text { Direct-acting antivirals } \\
\text { PBC/AlH } \\
\text { Corticosteroids } \\
\text { Ursodeoxycholic acid } \\
\text { Azathioprine } \\
\text { Mycophenolate mofetil } \\
\text { Infections } \\
\text { Chinolons } \\
\text { Penicillins } \\
\text { Esophageal varices } \\
\text { Proton pump inhibitors } \\
\text { Portal hypertension } \\
\text { Beta blocking agents } \\
\text { Hepatorenal syndrome } \\
\text { Terlipressin } \\
\text { Ascites } \\
\text { Diuretics } \\
\text { Albumin } \\
\text { Hepatic encephalopathy } \\
\text { Lactitol } \\
\text { Lactulose } \\
\text { Rifaximin }\end{array}$ & $\begin{array}{l}\text { Analgesics } \\
\text { Paracetamol } \\
\text { NSAIDs } \\
\text { Opioids } \\
\text { Antibiotics } \\
\text { Tetracyclines } \\
\text { Sulfonamides } \\
\text { and trimethoprim } \\
\text { Macrolides } \\
\text { Other antibiotics } \\
\text { Gastro-intestinal drugs } \\
\text { Antacids } \\
\text { H2-receptor antagonists } \\
\text { Propulsives } \\
\text { Stimulant laxatives } \\
\text { Bulk-forming laxatives } \\
\text { Cardiovascular drugs } \\
\text { Antithrombotics } \\
\text { Calcium antagonists } \\
\text { RAS-inhibitors }\end{array}$ \\
\hline
\end{tabular}

main domains of the checklist was the "management strategy'. We designed a safety classification to help healthcare professionals to efficiently judge the safety of a drug in a patient with cirrhosis. Safety classifications are used in other conditions where careful consideration is needed to judge the safety of a drug, such as Long QT-Syndrome, ${ }^{26}$ porphyria ${ }^{27}$ and pregnancy/lactation. ${ }^{28}$ All classifications have in common that the number of categories is limited, that a description is available why drugs are classified in a certain category and that a category can be related to an advice towards a healthcare provider. We think our safety classification results in concrete advices, thereby preventing dissatisfaction and alert fatigue of healthcare professionals.

The strengths of our study are the combination of evidence from the literature and expert opinion, the implementation in clinical decision support systems and the continuity. First, the published evidence of drugs in liver 
cirrhosis is variable, and studies often have a limited scope or a selective patient population. Combination with expert opinion adds the clinical and pharmacological experience to the published literature. This combination will make it possible to give specific advices, which is even more relevant in case little published literature is available. Second, the advices will be implemented in the two main clinical decision support systems in the Netherlands, automatically reaching all hospitals, community pharmacies and general practices. Healthcare professionals will receive a notification if a contraindicated drug is prescribed or dispensed to a patient with liver cirrhosis. This implementation can quickly result in a huge improvement in the medication safety of patients with cirrhosis in the Netherlands. We believe that this Dutch approach of monitoring the safety of drug use is unique, ${ }^{29}$ and hope to inspire others to implement this in their healthcare systems. Third, to safeguard continuity, it is important that this guideline will be updated regularly and that these updates will be included in new signals. The advices will get updated yearly if there is new literature or if we receive comments. This is a major advantage in comparison to all reviews published on this topic.

We expect that we will not perform a standard systematic review for all drugs. ${ }^{30}$ Albumin, for example, has been safely used for a long period of time in patients with liver cirrhosis and many studies have been published, also in patients with liver cirrhosis. In this case, we will include literature from the highest level of evidence and stop extracting if we have sufficient information to classify the drug. The expert panel will also decide whether sufficient information is collected to classify the drug. Another limitation is that we will evaluate a restricted number of drugs in this study. Future research can enlarge the amount of drugs evaluated. Also, this study will expose knowledge gaps in the current literature with respect to the pharmacokinetics and safety of certain drugs in liver cirrhosis. Specific pharmacokinetic or pharmacodynamic studies can possibly fill this gap. Another interesting future research area is the implementation; do healthcare professionals follow our advices? How can the information obtained in our study be used to improve official drug labelling? Ultimately, does our study result in optimisation of medication use, that is, reduction in the number of adverse drug events experienced by patients with liver cirrhosis?

In conclusion, this protocol describes a method to evaluate the safety and optimal dosage of drugs in patients with liver cirrhosis. This will lead to advices concerning the safety and optimal dosage of the drugs mostly used in liver cirrhosis and reveal gaps in the literature for future research.

\section{ETHICS AND DISSEMINATION}

Since this study does not directly involve human participants, it does not require ethical clearance. The advices generated by the method described in this study will be published on a website and in two drug databases (see Implementation section). We also aim to publish the generated advices of one or two drug classes in a peerreviewed journal and at conference meetings.

\section{Author affiliations}

${ }^{1}$ Health Base Foundation, Houten, The Netherlands

${ }^{2}$ Department of Pharmacy, Unit of Pharmacotherapy, -Epidemiology \&

-Economics, University of Groningen, Groningen, The Netherlands

${ }^{3}$ Department of Guideline Development, Dutch College of General Practice,

Utrecht, The Netherlands

${ }^{4}$ Department of Pharmacy, Radboud University Medical Center, Nijmegen, The Netherlands

${ }^{5}$ Department of Gastroenterology, Radboud University Medical Center, Nijmegen, The Netherlands

${ }^{6}$ Department of Pharmacy and Department of Intensive Care, Erasmus

University Medical Center, Rotterdam, The Netherlands

${ }^{7}$ Centre for Information on Medicines, Royal Dutch Pharmacists Association (KNMP), The Hague, The Netherlands

${ }^{8}$ Dutch Medicines Evaluation Board, Utrecht, The Netherlands

${ }^{9}$ De Brug Pharmacy, Almere, The Netherlands

${ }^{10}$ Department of Gastroenterology and Hepatology, Erasmus University Medical Center, Rotterdam, The Netherlands

${ }^{11}$ SIR Institute for Pharmacy Practice and Policy, Leiden, The Netherlands

Acknowledgements The authors thank Corine Colijn, Jan-Kees Huyts, Peter Mol, José Willemse, Froukje Harkes-Idzinga and Marleen Journée-Gillissen for their contribution towards study funding.

Contributors RW and SB wrote and drafted the protocol. MB, JD, NH, HM and $\mathrm{SB}$ contributed to the application for study funding. All authors contributed to the development of the study protocol and read and approved the final manuscript.

Funding This work was supported by ZonMw GGG-STIP grant number 836044009. ZonMw is the Dutch national organisation for health research and healthcare innovation. ZonMw's main commissioning organisations are the Ministry of Health, Welfare and Sport and the Netherlands Organisation for Scientific Research. ZonMw did not influence the content of the guideline.

Competing interests DB has received research grants from BMS, MSD and ViiV and has performed teaching for Abbvie, BMS, Gilead, MSD and ViiV, outside the submitted work. JD has received research grants from Abbvie and Janssen and has been a member of advisory boards of AbbVie, BMS, Gilead, Janssen, and Merck, outside the submitted work. HM has received research grants from AbbVie, Astellas, Novartis and Gilead and has been a member of advisory boards of AbbVie, Astellas and Novartis, outside the submitted work.

Provenance and peer review Not commissioned; externally peer reviewed.

Open Access This is an Open Access article distributed in accordance with the Creative Commons Attribution Non Commercial (CC BY-NC 4.0) license, which permits others to distribute, remix, adapt, build upon this work noncommercially, and license their derivative works on different terms, provided the original work is properly cited and the use is non-commercial. See: http:// creativecommons.org/licenses/by-nc/4.0/

\section{REFERENCES}

1. Tsochatzis EA, Bosch J, Burroughs AK. Liver cirrhosis. Lancet 2014;383:1749-61.

2. Blachier M, Leleu H, Peck-Radosavljevic M, et al. The burden of liver disease in Europe: a review of available epidemiological data. $J$ Hepatol 2013;58:593-608.

3. Mokdad AA, Lopez AD, Shahraz S, et al. Liver cirrhosis mortality in 187 countries between 1980 and 2010: a systematic analysis. BMC Med 2014;12:145.

4. Pugh RN, Murray-Lyon IM, Dawson JL, et al. Transection of the oesophagus for bleeding oesophageal varices. Br J Surg 1973;60:646-9.

5. Food and Drug Administration. Guidance for industry Pharmacokinetics in patients with impaired hepatic function: study 
design, data analysis, and impact on dosing and labeling. Updated 2003. http://www.fda.gov/downloads/drugs/

guidancecomplianceregulatoryinformation/guidances/ucm072123.pdf.

6. European Medicines Agency. Guideline on the evaluation of the pharmacokinetics of medicinal products in patients with impaired hepatic function. Updated 2005. http://www.ema.europa.eu/docs/en GB/document library/Scientific guideline/2009/09/WC500003122.pdf.

7. Verbeeck RK. Pharmacokinetics and dosage adjustment in patients with hepatic dysfunction. Eur J Clin Pharmacol 2008;64: 1147-61.

8. Delco F, Tchambaz L, Schlienger R, et al. Dose adjustment in patients with liver disease. Drug Saf 2005;28:529-45.

9. Gonzalez M, Goracci L, Cruciani G, et al. Some considerations on the predictions of pharmacokinetic alterations in subjects with liver disease. Expert Opin Drug Metab Toxicol 2014;10:1397-408.

10. Franz CC, Hildbrand C, Born C, et al. Dose adjustment in patients with liver cirrhosis: impact on adverse drug reactions and hospitalizations. Eur J Clin Pharmacol 2013;69:1565-73.

11. Westphal JF, Brogard JM. Drug administration in chronic liver disease. Drug Saf 1997;17:47-73.

12. Lewis JH, Stine JG. Review article: prescribing medications in patients with cirrhosis-a practical guide. Aliment Pharmacol Ther 2013;37:1132-56.

13. Steelandt J, Jean-Bart E, Goutelle S, et al. A prediction model of drug exposure in cirrhotic patients according to Child-Pugh classification. Clin Pharmacokin 2015;54:1245-58.

14. Schlatter C, Egger SS, Tchambaz L, et al. Pharmacokinetic changes of psychotropic drugs in patients with liver disease: implications for dose adaptation. Drug Saf 2009;32:561-78.

15. Rossi S, Assis DN, Awsare M, et al. Use of over-the-counter analgesics in patients with chronic liver disease: Physicians' recommendations. Drug Saf 2008;31:261-70.

16. Floor-Schreudering A, Geerts AF, Aronson JK, et al. Checklist for standardized reporting of drug-drug interaction management guidelines. Eur J Clin Pharmacol 2014;70:313-18.

17. OCEBM Levels of Evidence Working Group. The Oxford Levels of Evidence 2. Oxford Centre for Evidence-Based Medicine. http:// www.cebm.net/index.aspx $? 0=5653$

18. Raynor DK. User testing in developing patient medication information in Europe. Res Social and Adm Pharm 2013;9:640-5.
19. American Association for the Study of Liver Diseases, European Association for the Study of the Liver. Hepatic encephalopathy in chronic liver disease: 2014 practice guideline by the European association for the study of the liver and the American association for the study of liver diseases. J Hepatol 2014;61:642-59.

20. European Association for the Study of the Liver. EASL clinical practice guidelines on the management of ascites, spontaneous bacterial peritonitis, and hepatorenal syndrome in cirrhosis. J Hepatol 2010;53:397-417.

21. European Association For The Study Of The Liver. EASL clinical practice guidelines: management of chronic hepatitis $B$ virus infection. J Hepatol 2012;57:167-85.

22. European Association for Study of Liver. EASL clinical practice guidelines: management of hepatitis $\mathrm{C}$ virus infection. $J$ Hepatol 2014;60:392-420.

23. Heidelbaugh JJ, Sherbondy M. Cirrhosis and chronic liver failure: part II. complications and treatment. Am Fam Physician 2006;74:767-76.

24. Lo EA, Wilby KJ, Ensom MH. Use of proton pump inhibitors in the management of gastroesophageal varices: a systematic review. Ann Pharmacother 2015;49:207-19

25. Brouwers MC, Kerkvliet K, Spithoff K, on behalf of the AGREE Next Steps Consortium. The AGREE Reporting Checklist: a tool to improve reporting of clinical practice guidelines. BMJ 2016;352 i1152.

26. Woosley R, Romero K. QTdrugs list. https://www.crediblemeds.org/ (accessed 7 Mar 2016).

27. Thunell S, Pomp E, Brun A. Guide to drug porphyrogenicity prediction and drug prescription in the acute porphyrias. $\mathrm{Br} J \mathrm{Clin}$ Pharmacol 2007;64:668-79.

28. Addis A, Sharabi S, Bonati M. Risk classification systems for drug use during pregnancy: are they a reliable source of information? Drug Saf 2000;23:245-53.

29. van Mil JW. Pharmaceutical care in community pharmacy: practice and research in the Netherlands. Ann Pharmacother 2005;39:1720-5.

30. Moher D, Liberati A, Tetzlaff J, et al. Preferred reporting items for systematic reviews and meta-analyses: the PRISMA statement. BMJ 2009;339:b2535. 